\title{
Kinematic Analysis of Restored Gait after Transection and Grafting of Schwann Cell-Seeded Guidance Channels into Adult Rat Spinal Cord
}

\author{
Kyoung-Suok Cho, Xiao-Ming Xu*, Véronique Guénard*, Mary Bartlett Bunge*
}

\author{
Department of Neurosurgery, Catholic University Medical College, \\ Seoul, Korea \\ The Miami Project to Cure Paralysis, Department of Neurological Surgery, \\ University of Miami School of Medicine, Miami, Florida, USA*
}

\begin{abstract}
Schwann cells (SCs) have been shown to effectively promote axonal regeneration in both peripheral nervous system and central nervous system. We are testing the ability of Scs to enhance regeneration in adult rat spinal cord when they are present in guidiance channels grafted into transected cords. And we performed detailed kinematic analysis of recovery process using a computerized motion analysis system after Schwann cell transplantation into midthoracic area. SCs were purified in culture from adult rat sciatic nerve, suspended in Matrigel : DMEM (30:70), and seeded into semipermeable PAN/PVC guidance channels ( $2.6 \mathrm{~mm} \mathrm{ID} \mathrm{x} 8 \mathrm{~mm}$ long, 50kDa MW cutoff) at a final density of $120 \times 10^{6}$ cells $/ \mathrm{ml}$. Adult Fischer rat spinal cords were transected at T8 and the T9 segment, the spinal cord was removed to create a $4 \mathrm{~mm}$ gap. The rostral and caudal stumps of the cord were each inserted $1 \mathrm{~mm}$ into the channel. One month after grafting, a vascularized tissue cable was present within the channel bridging the two ends of the spinal cord. Within the cable, numerous myelinated and unmyelinated axons were observed. Fast Blue retrograde tracing showed that the majority of neurons whose axons regenerated into the channel were located in spinal cord gray matter. The labeling could be traced 9 segments rostrally to C7 and 9 segments caudally to L5. Axons from dorsal root ganglion neurons also regenerated into the channel. Lack of immunostaining for serotonin (5-HT) and dopamine beta hydroxylase (DBH) indicated that supraspinal axons from raphe nuclei (5-HT immunoreactivity) did not grow into the channel. We conclude that SCs in guidance channels serve as a cellular bridge that stimulates axonal regeneration of both ascending and descending spinal cord neurons. And we confirmed restored gait after transplantation with computerized motion analysis system.
\end{abstract}

Key word: central nervous system regeneration, polymeric guidance channels, spinal cord transplantation, cellular bridge, gait motion analysis

Spinal Surgery $12(2): 123 \sim 144,1998$

(Received : January 8, 1998, Accepted : March 9, 1998)

Address reprint request to: Kyoung-Suok Cho, M.D., Ph.D., Department of Neurosurgery, Uijongbu St. Mary's Hospital, Catholic University Medical College, 65-1, Kumoh-dong, Uijongbu, 480-130, Korea 


\section{INTRODUCTION}

When peripheral nerve is injured, axons regenerate successful into the distal stump leading eventually to a considerable degree of functional recovery [26,73]. In contrast, regeneration of lesioned axons in the central nervous system (CNS) of adult mammals, including humans, is usually abortive. Ramöny Cajal [61] concluded that the failure of CNS regeneration was due to an absence of neurotrophic and neurotropic substances in the CNS rather than to an intrinsic neuronal deficit for regeneration. By grafting pieces of sciatic nerve into CNS areas, he (among others) obtained evidence that CNS axons were able to regenerate into the peripheral nervous system (PNS) environment suggesting that Schwann cells (SC) provided the required factors. Using neuroanatomical tracing methods developed subsequently, Richardson et al. [65, 66] clearly demonstrated substantial regeneration of CNS axons into peripheral nerve grafts implanted into lesioned rat spinal cords.

One of the major cellular components of peripheral nerve is the SC. When a peripheral nerve is injured, the axons distal to the damage degenerate, but the SC and their basal lamina (bands of Büngner) remain; it is into this tunnel of basal lamina filled with SC that axonal regeneration occurs. SC produce a number of trophic factors including nerve growth factor (NGF) $[8,40]$, brain-derived neurotrophic factor (BDNF) [1, 53], and ciliary neurotrophic factor (CNTF) [29, 64]. They synthesize and secrete extracellular matrix (ECM) molecules such as laminin [15, 16], which is known to modulate neurite outgrowth [21], and express a variety of cell adhesion molecules $[13,19$, $46,67]$. All these components have been suggested to play roles in supporting neuronal survival and axonal regeneration [71].

Although SC are not normally resident in the spinal cord, they support axonal regeneration when transplanted into lesioned adult CNS [37]. Following spinal cord injury in a number of experimental paradigms [52, 59], SC grafted into the lesion promoted axonal growth. SC have also been shown to promote axonal regeneration in other regions of the CNS such as the optic nerve [35, 37], the septohippocampal system $[48,54,58]$, and the diencephalon $[55,56]$.

In recent years, guidance channels made of materials of biological or synthetic origin $[2,28,72]$ have been used to study both PNS and CNS regeneration. Guidance channels can provide a controlled environment in which axons can elongate in response to the channel content, scar tissue invasion is limited, and humoral factors accumulate $[50,51]$. The content of the guidance channels may be easily modified by the addition of various cellular and/or humoral elements prior to implantation.

Gait analysis using foot print measurements [7, 18], grid walking ability [22], combined behavioral tests [3, 23, 24], Inclined Plane test [32], and sensorimotor tests [45] have been used to measure motor function recovery after spinal cord injury (SCI). The two most commonly used motor testing methods are the Tarlov Scale and the Inclined Plane tests [33]. In the original Tarlov Scale [34], spontaneous motor behavior of a cat in the open field are evaluated and arbitrary values assigned to each category of behavior. Many investigators have modified this method by adding subcategories of motor behavior to be evaluated. In the inclined plane method, the maximum angle of the floor plane at which the animal can maintain its position is measured. Different laboratories have also used some modifications of this method. The inclined plane test does not directly measure motor behavior however.

We carried out detailed kinematic analyses of foot trajectories in adult rats after spinal cord transplantation with Schwann cell seeded guidance channel with computerized motion analysis combined with video recordings. However, no attempts have been made in employing kinematic analysis for the evaluation of motor deficits in rats following spinal cord transplantation. Trajectories of all four feet were measured before and after spinal cord transplantation in adult rats. 
In the present study, we tested the ability of SC seeded into semipermeable guidance channels to foster axonal regeneration after grafting into transected spinal cords. Four questions were addressed: 1) do axons, particularly those originating from CNS neurons, grow into the guidance channel; 2) does axonal growth into the guidance channel depend upon the implanted SC; and 3) from what areas of the CNS do axons extending into the channel originate? 4) Can we confirm the restored gait after grafting? A preliminary report of this work has appeared [75].

\section{MATERIALS AND METHODS}

Twenty-two female Fischer rats (Charles River Laboratories, Wilmington, MA) weighing 160-180g received implants; 14 received grafts of SC in Matrigel (that contains basal lamina components; Collaborative Research Inc., Bedford, MA) within guidance channels, whereas eight received control channels containing only Matrigel. Sciatic nerves from 15 Fischer rats weighing 180-200g were used for the preparation of purified populations of SC.

\section{$<$ Purification and amplification of SC $>$}

Purified SC was derived from sciatic nerve by a technique developed in this laboratory [57]. The animals were killed by ether inhalation, and their sciatic nerves were removed under aseptic conditions and then placed into Liebovitz's L-15 medium (Gibco Laborarories, Grand Island, NY) supplemented with $50 \mathrm{U} / \mathrm{ml}$ penicillin and $0.05 \mathrm{mg} / \mathrm{ml}$ steptomycin. After the connective tissue and epineurium were stripped off, the nerves were chopped into 1 to $3 \mathrm{~mm}$ explants. Ten to fifteen explants were placed in $35 \mathrm{~mm}$ Corning tissue culture dishes (Baxter, Stone Mountain, GA) with low level of Dulbecco's modified Eagles's medium (DMEM; Gibco), supplemented with 10\% fetal calf serum (FCS; Gibco), penicillin $(50 \mathrm{ml} / \mathrm{ml})$, and streptomycin $(0.05 \mathrm{mg} / \mathrm{ml})$. When the outgrowth of migratory cells (predominantly fibroblast) reached a near-confluent monolayer around the explants (7-10 days), the explants were transferred to new culture dishes with fresh medium.

After three or four such passages requiring approximately 4-5 weeks, the cells that emerged from the explants were primarily SCs. The explants were then transferred to a new $35 \mathrm{~mm}$ dish containing 1.25 $\mathrm{U} / \mathrm{ml}$ dispase (Boehringer Mannheim Biochemicals, Indianapolis, IN), $0.05 \%$ collagenase (Worthington Biochemicals Corp., Freehold, NJ), and 15\% FCS in DMEM for incubation overnight at $37^{\circ} \mathrm{C}$ in $7 \% \mathrm{CO} 2$. The following day, the explants were dissociated by gentle trituration through a pipette, washed two to three times in DMEM/10\% FCS, and seeded onto poly-L-lysine-coated $100 \mathrm{~mm}$ tissue culture dishes in DMEM/ $10 \%$ FCS at a density of $2 \times 10^{6}$ cells/dish. Cells were allowed to attach overnight, and the cultures were refed with DMEM/10\% FCS supplemented with $20 \mathrm{ILg} / \mathrm{ml}$ pituitary extract (BTI Stoughton, MA) and $2 \mu \mathrm{M}$ forskolin (Sigma, St. Louis, MO) [60].

After 5-7 days, the cultures reached confluence (approximately $4-5 \times 10^{6}$ cells/dish). Cells were removed by rinsing several times in $\mathrm{Ca}^{2+}$ and $\mathrm{Mg}^{2+}$ free Hanks balanced salt solution (CMF; Gibco) followed by a brief treatment with $0.05 \%$ trypsin (Gibco) / 0.02\% EDTA (Gibco) in CMF. Cells were washed twice in DMEM/10\% FCS and passaged into new poly-L-lysine-coated dishes at a density of $2 \mathrm{x}$ $10^{6}$ cell $/ 100 \mathrm{~mm}$ dish. When the cells reached confluence again, they were either collected for filling the guidance channels or for further expansion.

\section{< Guidance channel preparation >}

Guidance channels $(2.6 \mathrm{~mm}$ inner diameter, $3.0 \mathrm{~mm}$ outer diameter, kindly provided by Dr. Patrick Aebischer) are composed of a $60: 40$ acrylonitrile : vinylchloride copolymer (PAN/PVC) and fabricated by conventional spinning techniques $[5,17]$. The tube features a semipermeable, smooth inner skin with a nominal molecular weight cutoff of $50 \mathrm{kDa}$. The inner skin is connected to an outer skin by an open 
trabecular network, which provides structural strength. Prior to seeding, the tube was cleaned and sterilized as described by Aebischer et al [2].

SC were collected by centrifugation after treatment with $0.05 \%$ trypsin and $0.02 \%$ EDTA in CMF for 3-5 minutes at $37^{\circ} \mathrm{C}$ and washed in DMEM. A sample was counted in hemocytometer. Pelleted SC were then gently resuspended in a $70: 30(\mathrm{v}: \mathrm{v})$ solution of DMEM : Matrigel at a final density of $120 \times 10^{6}$ cells/ml and drawn into a $35-40 \mathrm{~mm}$ channel by suction. The channel was closed at both ends with PAN/PVC glue and kept in DMEM for 24 hours at $37^{\circ} \mathrm{C}$. During this time, cable of aligned SC formed inside the channel because of a "syneresis" effect. Before grafting, the channel was cut into 10-mm-long pieces, and the ends were closed with glue. Control channels were filled with a $70: 30$ solution of DMEM : Matrigel in a similar way with no SC added.

In three cases, $\mathrm{SC}$ was prelabeled with bisbenzimide (Hoechst 33342; Sigma) before transplantation according to the method of Baron-Van Evercooren et al [9]. The dye binds to DNA and remains for long periods in the cell nucleus. Monolayers of purified SC were incubated at $37^{\circ} \mathrm{C}$ in DMEM $/ 10 \%$ FCS containing $10 \mu \mathrm{l} / \mathrm{ml}$ of Hoechst 33342 for 1 hour. After several washes in DMEM, cells were trypsinized and collected for placement into guidance channels.

The purity of the cultured SC was quantified on the day of implantation. At the same time the channels were filled, cells were seeded onto collagen-coated Aclar coverslips (Allied Signal, Pottsville, PA) in DMEM/ 10\% FCS. Schwann cells were identified by immunocytochemical labeling for S-100 protein. Cells were fixed for 20 minutes in Lana's fixative, a modified Zamboni fixative [77] containing 4\% paraformaldehyde and $0.4 \%$ picric acid in $0.16 \mathrm{M}$ phosphate buffer [42], followed by permeabilization in $0.01 \mathrm{M}$ phosphate-buffered saline (PBS) with $0.3 \%$ Triton X-100. After blocking with L-15/10\% heatinactivated horse serum (HIHS), the cells were incubated in anti-S100 antibody (1:100; Dakopatts, Santa Barbara, CA) overnight at $4^{\circ} \mathrm{C}$. The following day, the cells were incubated with fluorescentconjugated goat anti rabbit antibody (1:100; Cappel / Organon Teknika Corp., Durham, NC) for 45 minutes at room temperature.

The purity of SC was determined by comparing the number of S-100-immunoreactive cells with the number of Hoechst-labeled nuclei under fluorescence microscopy.

\section{< Guidance channel implantation >}

The rats were anesthetized with an intraperitoneal injection of pentobarbital sodium $(40 \mathrm{mg} / \mathrm{kg}$; Anthony Products Co., Arcadia, CA). A subcutaneous injection of $100 \mathrm{mg}$ cefazolin sodium (Kefzol; Eli Lilly and Company, Indianapolis, IN) was given before surgery, and Lacrilube Ophthalmic Ointment (Allergan Pharmaceuticals, Irvine, CA) was applied to the eyes to prevent drying. The animals were placed on a heating pad to maintain body temperature at $37^{\circ} \mathrm{C} \pm 5^{\circ} \mathrm{C}$. All surgical procedures were performed under sterile conditions. A multilevel laminectomy was performed including T7-T10 thoracic vertebrae and the cord segments (T8-T11) underneath was exposed (Fig. 1A). The dura was incised longitudinally and pulled laterally. A spinal cord transection was made at the T8 level by a combination of cutting and aspiration (Fig. 1B). The T9-T11 cord segments were removed. In addition, spinal roots from the immediate rostral cord (T6-T8) were also removed. The guidance channel was grafted into the lesion site and the rostral cord was inserted approximately $1 \mathrm{~mm}$ into the now uncapped proximal opening of the channel (Fig. 1C). The distal end of the channel remained capped. The dura was then pulled to wrap the sides of the channel, and a piece of dura film (Dura film; Codmann Surlef, Inc., Randolph, MA) was positioned over the graft. The muscle was skin were then closed in layers.

\section{$<$ Postoperative care >}

Immediately after implantation, rats were returned 

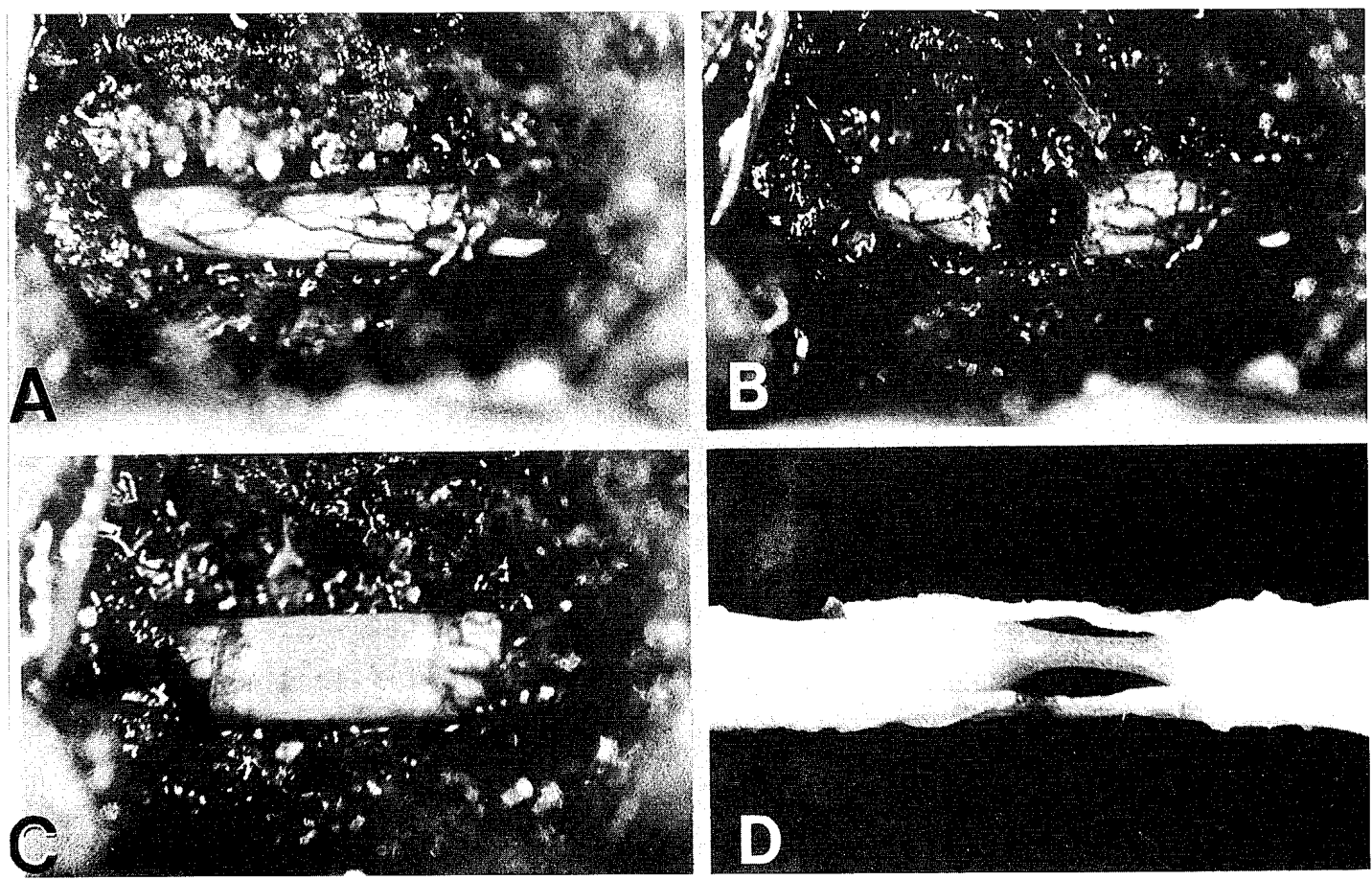

Fig. 1. Representative photos showing the surgical procedures:

A: Dorsal exposure of the four segments (T8-T11) of the spinal cord.

$\mathrm{B}$ : Complete transection of the cord at $\mathrm{T} 8$ and the removal of T9-T11 caudally.

C: Attachment of a SC-seeded guidance channel to the rostral cut end of the cord.

D: One month after transplantation, the graft was found to be well attached to the host spinal cord, and regenerated cable was seen.

their cage with water and food made easily accessible. A subcutaneous injection of $5 \mathrm{ml}$ lactate Ringer solution (Kendall McGaw Lab., Inc., Irvine, CA) was administered for the first 2 days to compensate for blood loss. Ceazolin sodium (100 mg/day) was injected subcutaneously for the first week to prevent infection. Bladder expression was performed three times a day for the first week and twice a day thereafter until sufficient empty of the bladder returned. During the period, $0.5 \mathrm{ml}$ of SMZTM (Sulfamethoxazole $40 \mathrm{mg} / \mathrm{ml}$ and $8 \mathrm{mg} / \mathrm{ml}$ oral suspension; Phoenix Pharmaceutical, Inc., St. Joseph, MO) was given daily to prevent urinary tract infection. Cecon oral solution (10 mg ascorbic acid, Abbott Laboratories, North Chicago, IL) was given daily in drinking water to acidify urine and to accelerate wound healing. All animals survived for approximately 30 days except three cases in which animals received injections of fast blue (FB); an additional 4-5 days were then required for retrograde transport of the dye.

\section{$<$ Tissue processing $>$}

\section{Perfusion}

The rats were overdosed by an intraperitoneal injection of pentobarbital sodium $(60 \mathrm{mg} / \mathrm{kg})$. A pressure-perfusion system was used at 120-140 $\mathrm{mm} \mathrm{Hg}$ to infuse, via the aorta, $200 \mathrm{ml}$ physiological saline (heparinized with 10 units $/ \mathrm{ml}$ ) followed by 500 $\mathrm{ml}$ Lana's fixative. The rostral spinal cord along with implanted guidance channel (Fig. ID) was carefully dissected out and postfixed in Lana's solution for 1 hour. Transverse slices taken 3,6 , and $9 \mathrm{~mm}$ from the 
beginning of the channel were transferred to a fixative solution containing $2 \%$ glutaraldehyde and $3 \%$ sucrose in $0.1 \mathrm{M}$ phosphate buffer $(\mathrm{pH} 7.4)$ overnight for light and electron-microscopy preparation. The intervening proximal, middle, and distal segments were transferred to a solution containing $20 \%$ sucrose in $0.1 \mathrm{M}$ phosphate buffer overnight. These segments were cut longitudinally for immunohistochemistry.

\section{Light and electron microscopy}

The transverse sections of guidance channels with their contained tissue cables were rinsed in $0.1 \mathrm{M}$ phosphate buffer before immersion in $1 \%$ osmium tetroxide in $0.1 \mathrm{M}$ phosphate buffer for 2-16 hours. The tissue was then rinsed in phosphate buffer, dehydrated in graded ethanol, ending in propylene oxide, and embedded in Epon-Araldite (Electron Microscopy Sciences, Fort Washington, PA). Onemicrometer, semithin plastic sections were stained in $1 \%$ Toluidine blue-1\% methylene blue-1\% sodium borate. The myelinated axons in SC-seeded or Matrigel-only channels were counted in these sections and analyzed statistically. Data were expressed as the mean \pm SEM (standard error of the mean). All statistical analysis was performed with Statistica (Statsoft, Inc., Tulsa, OK), a commercially available computer software program. Comparisons involved two levels of analysis because of the nature of the preparation. The first analysis used a mixed-design analysis of variance (ANOVA) with the experimental group (i.e., SC-seeded or Matrigel-only channel) as a between factor and with distance (i.e., $3 \mathrm{~mm}$ or $6 \mathrm{~mm}$ ) as a repeated measure. Posttest comparison of the individual means was made using the Tukey HSD method. A separate, one-way ANOVA was performed for the measure at $9 \mathrm{~mm}$ where the tissue cable could not be evaluated in some preparations, because it was too close to the capped end of the channel. For electron microscopy, thin cross sections of tissue cables were cut at $3 \mathrm{~mm}$ from the beginning of the channel, stained with uranyl acetate and lead citrate, and examined in a Philips CM10 electron microscope. Electron micrographs were taken from a cross section of each of the four cables studied in a randomized manners the micrographs were taken near the four corners and the center of each grid square when myelinated or unmyelinated axons were present. Forty-six grid squares were photographed in all. These micrographs were used to count myelinated and unmyelinated axons to estimate the ratio between the two populations.

\section{Immunohistochemistry}

The proximal, middle, and distal segments of the guidance channels were embedded and immediately frozen on dry ice. Ten-micrometer sections were cut longitudinally on acryostat (Bright Instrument Co., Huntington, England) and mounted on gelatin-coated slides. Before incubation, the sections were permeabilized and blocked with $0.3 \%$ Triton X$100 / 10 \%$ normal goat serum (NGS) in 0.01 M PBS for 16 minutes. Primary antibodies were then applied to the sections overnight at $4^{\circ} \mathrm{C}$ Polyclonal rabbit antiglial fibrillary acidic protein antibody (GFAP; Incstar Corp., Stillwater, MN) was used without dilution to identify astrocytes. Polyclonal rabbit antiS-100 antibody was used at $1: 100$ as a marker for SC. Monoclonal mouse anti-SMI-31 antibody was used at $1: 2,500$ (in $50 \mathrm{mM}$ Tris-HCl-buffered saline, $\mathrm{pH}$ 7.4) to identify axons. Polyclonal rabbit anticalcitonin gene-related peptide antibody (CGRP, kindly provided by Dr. Ian Dickerson) was used at 1 : 200 as a marker for axons of peripheral origin. Polyclonal rabbit antiserotonin antibody $(5-\mathrm{HT}$; Incstar) was used at 1:100 as a marker for serotonergic axons, and polyclonal rabbitantidopamine 13-hydroxylase antibody (DBH; Incstar) was used at 1:200 as a marker for axons descending from locus coeruleus and surrounding regions of the brain stem. The following day, the sections were incubated with either fluoresceinconjugated goat anti-rabbit (1:100; Cappel/Organon Teknika Corp.) or rhodamine-conjugated rabbit antimouse antibody (1 : 100; Cappel / Organon Teknika Corp.) for 45 minutes at $37^{\circ} \mathrm{C}$. Slides were washed, mounted, and examined by Zeiss Axiophot 
fluorescence microscopy.

\section{$<$ Retrograde tracing $>$}

In three animals grafted with SC-seeded guidance channels, a retrograde fluorescence tracer, Fast Blue (FB, 0.2-0.5 $\mu 1$ in a $3 \%$ aqueous suspension), was injected into the middle of the tissue cable 30 days after grafting. The FB solution was sonicated for 5-10 minutes prior to injections. Pressure injections were made using a glass micropipette (30-50 $\mu \mathrm{m}$ tip) attached to a $1 \mu \mathrm{l}$ Hamilton syringe. After injection, the surgical exposure was closed, and the animals were maintained for 4-6 days before being perfused with saline followed by $4 \%$ ice-cold buffered paraformaldehyde. The grafts, the rostral portion of the spinal cords including all dorsal root ganglia (DRG), and brains were removed and stored in $20 \%$ sucrose in $0.1 \mathrm{M}$ phosphate buffer. Tissue slices from the injection site and the host spinal cord immediately rostral to the channel (T6-T7) were cryosectioned longitudinally at $30 \mu \mathrm{m}$. From each case, approximately 2,500 serial cross-sections were prepared from T6 through the entire brain. The sections were mounted in order onto gelatin-coated slides and cover slipped. The extent of the injection was carefully evaluated to ensure that the injection was confined and that no spread of dye to the interface had occurred. The positions of every labeled cell in each spinal segment and associated DRG were plotted and counted under the Zeiss Axiophot fluorescence microscope at an excitation wavelength of 340-380 $\mathrm{nm}$. Labeled cells in adjacent sections were carefully followed to 2 confirm that no cell was counted twice. Data were expressed as the mean \pm SEM.

\section{< Video recording of treadmill locomotion >}

Treadmill locomotion holds many advantages over other methods. It allows us to obtain numerous step cycles at constant speed so that averages of step cycle could be calculated. The use of a treadmill also facilitates video recording because the rats remain stationary and within the camera's field center. Videorecording of overground locomotion was very difficult. Lastly, treadmill locomotion forces the animal to expose their motor deficits. Our treadmill was equipped with electric grids that deliver low voltage shocks whenever the rats fell off the belt. Most of the animals learn to stay on the treadmill belt after receiving one or two shocks. A few animals failed to perform consistent locomotion in control experiments and they were not used in further studies.

Lateral views of rats walking on a treadmill were recorded with a Panasonic Video Camera (WVD5100) with a time resolution of $33.3 \mathrm{~m} \mathrm{sec}(30$ frames per second). To facilitate the digitizing process, the major joints of the fore- and hindlimbs were marked with black paint. To reduce blurring, the camera shutter speed was set at $1 / 2000$ second. The position of the feet (represented by the metacarpal and metatarsal joints) in two dimensional space was then digitized using the 2-D Peak Performance Motion Analysis System (Peak Performance Technologies Inc., Englewood, Colorado). Running speed of the treadmill was set so as to allow the animals to walk or at least 60 seconds without falling off the treadmill. In control experiments, locomotor data were taken at several speeds ranging from $40 \mathrm{~cm}$ to $80 \mathrm{~cm}$ per second. However, following spinal cord transplantation, tests were run at the speed an animal could most consistently walk for more than 60 seconds.

\section{< Motion Analysis >}

Our study analyzed foot trajectories rather than limb joint angels because of the difficulties in localizing the latter in the rat. Skin flaps tend to mask the position of the joints. In each picture frame, $X-Y$ coordinates of right and left metacarpal joints, as well as right and left metatarsal joints, were digitized. Data points were collected form several different joint positions. However, detailed analyses were carried out on only the metatarsal and metacarpal joints. 


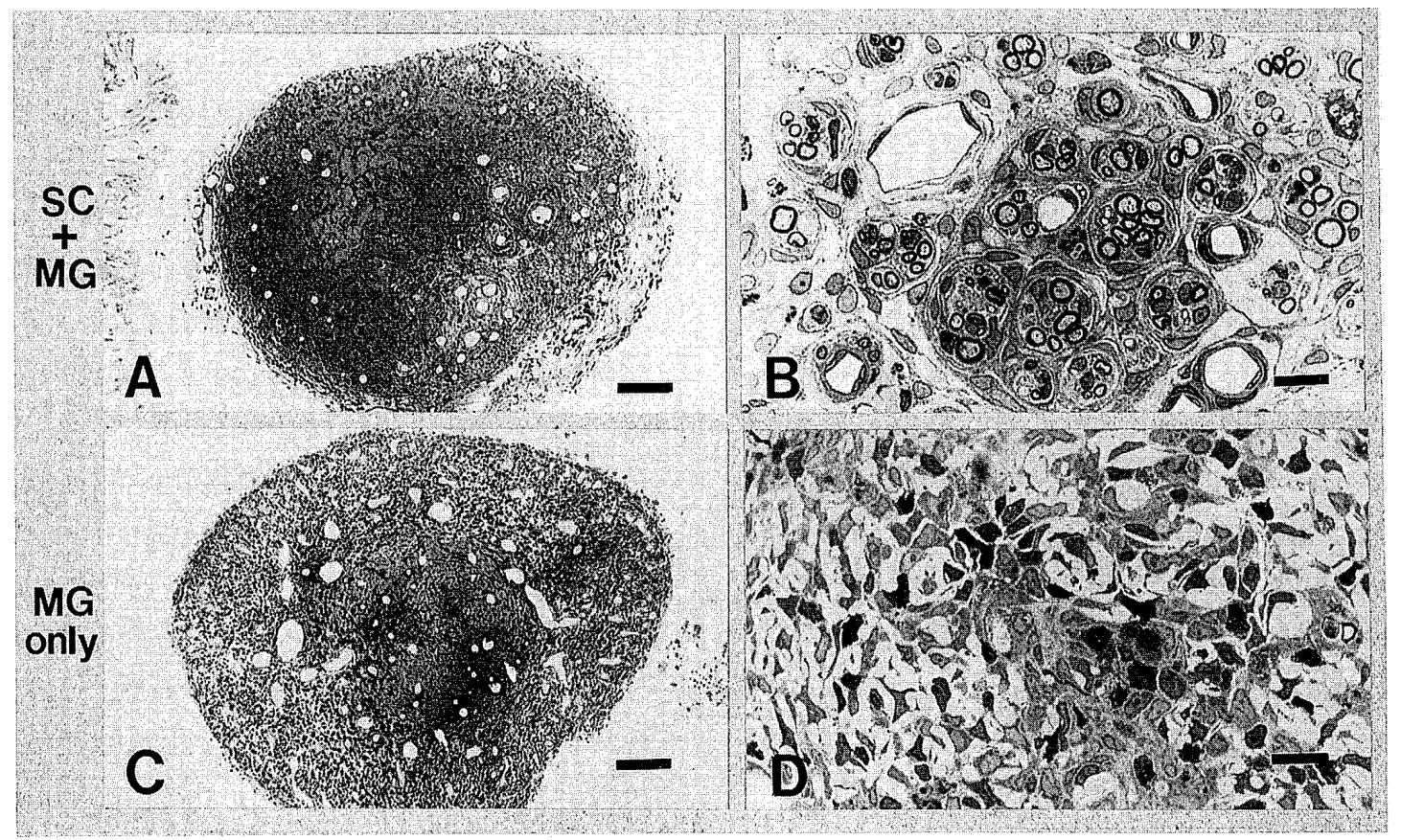

Fig. 2. Micrographs of Toluidine blue-stained plastic sections showing cross-sections of the midpoint of a Sc-seeded guidance/Matrigel ( $\mathrm{SG}+\mathrm{MG}$ ) channel (A, B) and Matrigel only (MG only) channel (C, D) 30 days after transplantation. Higher magnifications of demarcated regions in these sections are shown on the right (B), where fascicles of myelinated axons are clearly seen. But few myelinated axon was seen in Matrigel only cable (D). Scales of bar in A \& C = 100 $\mathrm{mm}$. Scales of bar in B \& D = 10 $\mu$ m.

Trajectories of all four feet were reconstructed in twodimensional space. The software used to digitize limb position doubles the number of picture frames from 30 to 60 per second by interpolating neighboring lines. This manipulation resulted in a time resolution of approximately $16.67 \mathrm{~ms}$ per frame of picture. At least four seconds of consecutive data were digitized to be included for further analysis of the trajectories. Approximately ten to fifteen step cycles occurred in four seconds of walking (approximately 400 frames of pictures) at speeds ranging from 40 to $80 \mathrm{~cm} / \mathrm{s}$. The raw data were then smoothed with a Butterworth digital filter $(10 \mathrm{HZ})$. Initially, the timing of foot touch-down and lift-off were made during the digitizing session by examining each picture frame. Further analysis of each step cycle in the X-Y coordinates revealed that minimum $\mathrm{X}$-values occurred at foot liftoff while maximum $\mathrm{X}$-values occurred at foot touch down.

\section{RESULTS}

Spinal cord transection at the T8 level interrupted both ascending and descending spinal pathways. The combination of cutting with microscissors and aspiration minimized damage at the transection site; the cut edge of the rostral was well preserved and the dorsal spinal vessels could be followed to the rostral cut end (Fig. 1B). One month later, the guidance channel was well attached to the rostral cord (Fig. 1D). In both SC-seeded and Matrigel-only channels, connected to the rostral stump of the spinal cord. The cable extended the entire length of the guidance channel (approximately 9-10 mm, Fig. 1D). 


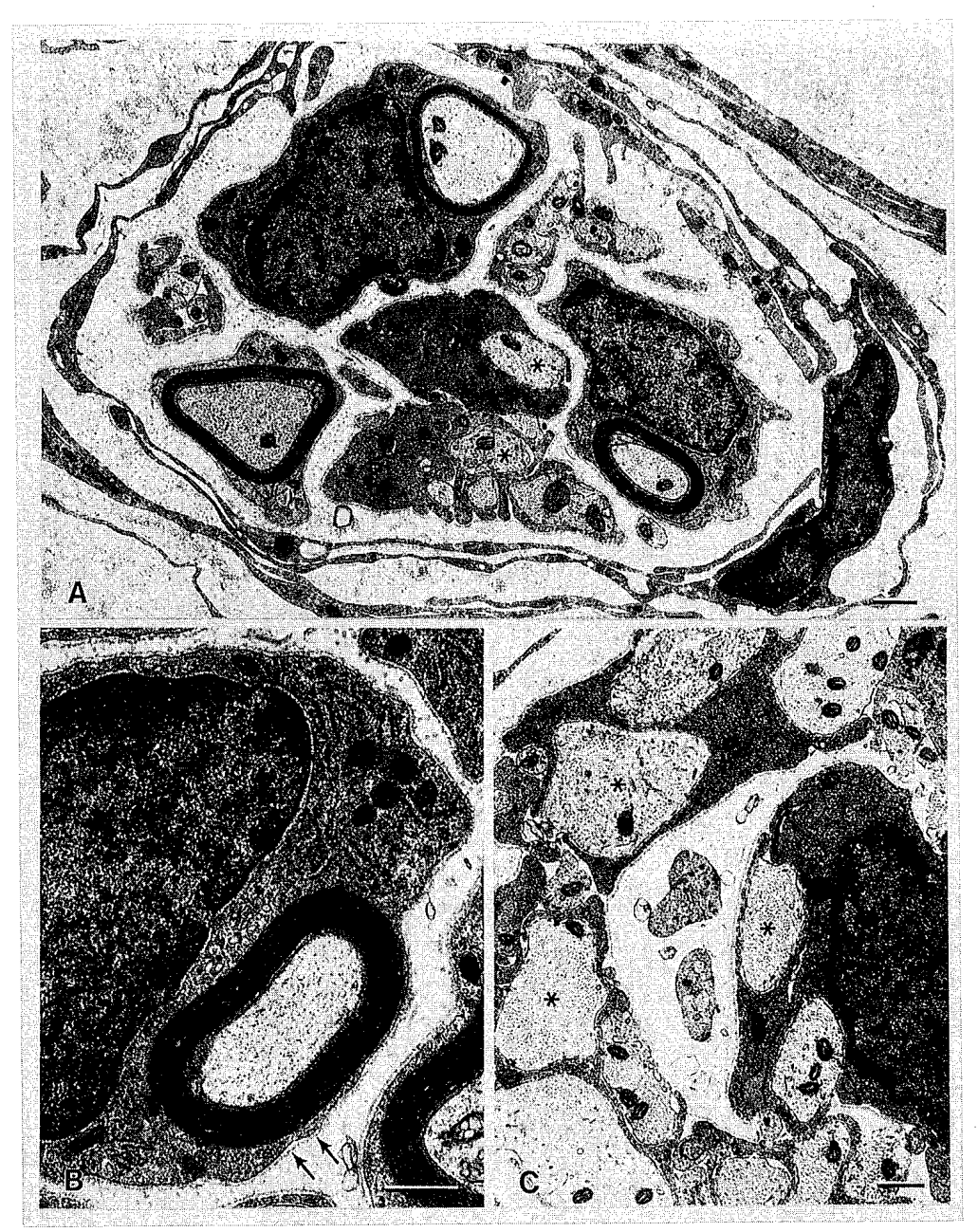

Fig. 3. Electron micrographs of an SC-containing tissue cable $3 \mathrm{~mm}$ from the beginning of the channel 30 days after transplantation showing (A) a typical fascicle of axons either myelinated (stars) or (B) ensheathed (asterisks) by SC within a perineurial-like structure a typical SC surrounded by basal lamina (arrows). Scale of bar = $0.5 \mu \mathrm{m}$.

\section{< Light and electron microscopy >}

One month after grafting, numerous myelinated axons were observed in the SC-containing cable. In Toluidine blue-stained semithin cross-sections (Fig. 2), a tissue cable could be seen at $3 \mathrm{~mm}, 6 \mathrm{~mm}$, and 9 $\mathrm{mm}$ from the proximal opening of the channel. A few layers of connective tissue cells that formed an epineurium-like structure and contained numerous blood vessels of different calibers surrounded the cable. Fibroblasts formed compartments enclosing areas of Matrigel. Higher magnifications of plastic sections demonstrated that fascicles of myelinated axons existed in the guidance channels (Fig. 2A,B). Ultrastructurally, these fascicles were found to be confined within perineurial-like structures formed by flattened, curving cells (Fig. 3A). Within each fascicle, typical SCs were surrounded by basal lamina (Fig. 3). A SC either myelinated a single axon or ensheathed one or many unmyelinated axons (Fig. $3)$, as is typical in the PNS. Axonal counts from randomly selected regions in four tissue cables indicated that there were approximately four times more unmyelinated than myelinated axons (4:1). The number of myelinated axons ranged from 176 to 1,208 in the sections cut at $3 \mathrm{~mm}$ in 14 cases studied. The mean number of myelinated axons at $3 \mathrm{~mm}$ was $501(\mathrm{SEM}=83)$; at 6 $\mathrm{mm}$, it was 306 (SEM = 76); and, at $9 \mathrm{~mm}$, it was $82(\mathrm{SEM}=47)$. In Matrigel-only channels $(\mathrm{n}=8)$, the average number of myelinated axons at $3 \mathrm{~mm}$ was $71(\mathrm{SEM}=$ 26); at $6 \mathrm{~mm}$, it was $20(\mathrm{SEM}=7)$, and, at $9 \mathrm{~mm}$, it was $2($ SEM $=1)$. The mixed-design ANOVA revealed that the interaction of groups (i.e., $\mathrm{SC}$-seeded or Matrigel-only) by distance (i.e. $3 \mathrm{~mm}$ or $6 \mathrm{~mm}$ ) was statistically significant $(\mathrm{F}=12.57 ; \mathrm{P}<0.01)$. It also showed a significant difference statistically $(\mathrm{P}<$ 0.01 ) between groups and between the repeated measures. The Tukey posttest comparing the individual means showed a statistically significant difference $(\mathrm{P}<0.01)$ between the number of myelinated axons in the SC-seeded and the Matrigelonly channels at both 3 and $6 \mathrm{~mm}$. These results confirmed that SC in guidance channels supported 

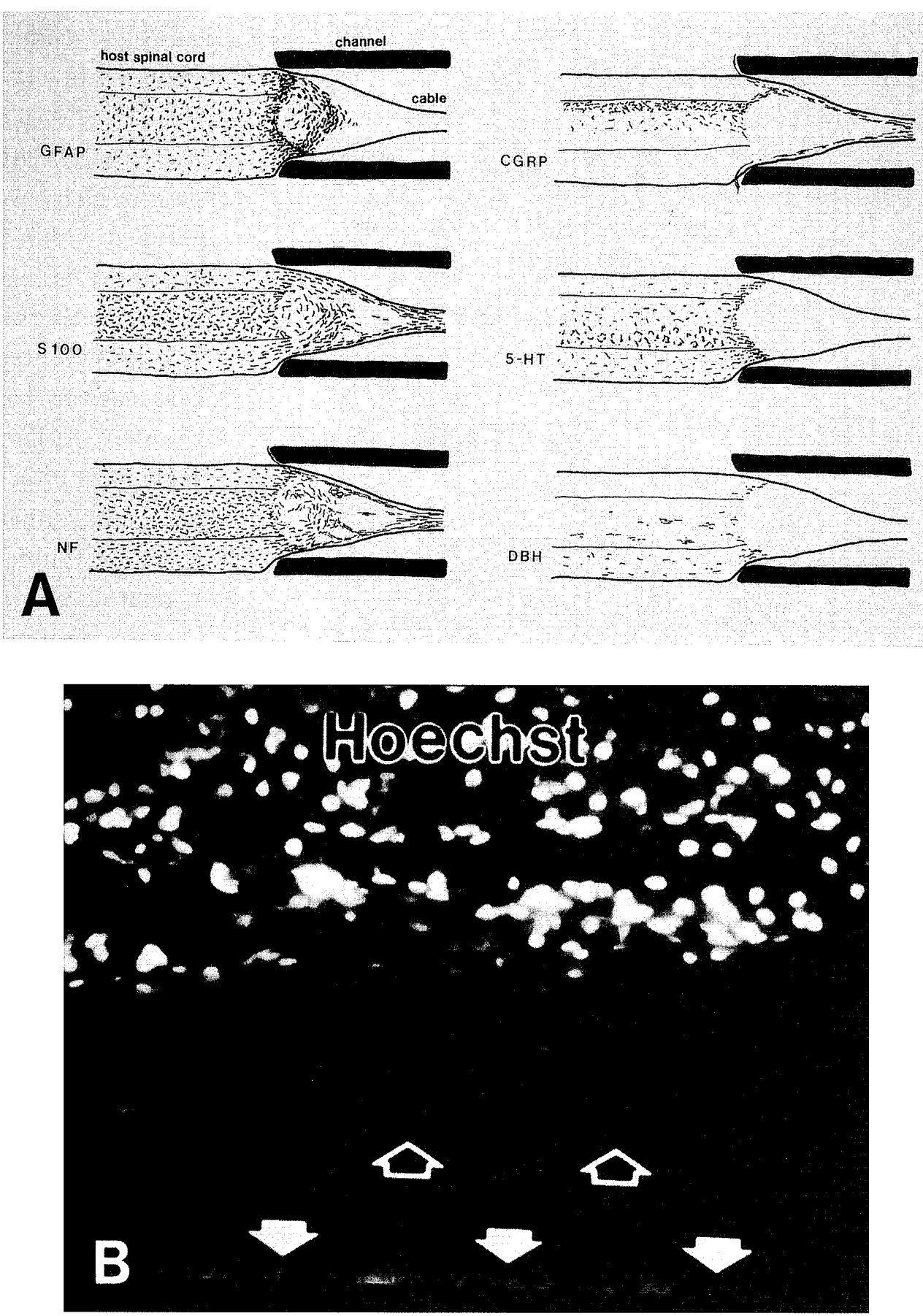

Fig. 4.

A: Summary of the immunohistochemical observations:

1) astrocytes did not migrate $>0.5-1.0 \mathrm{~mm}$ into the guidance channels (GFAP);

2) cultured SC survived in the graft and were associated with ingrowing axons (S-100),

3) axons grew into the guidance channel and extended to the end of the cable (NF, SMI $31^{+}$);

4) some axons were probably PNS origin (CGRP); and

5) supraspinal projecting axons from brain-stem raphe nuclei (5-HT) and locus coeruleus and adjacent cells (DBH) accumulated at the host-graft interface and did not grow into the guidance channel.

B: Photomicrograph of fluorescent structures illustrates that numerous Hoechst dyes labeled Sc was present in the cable indicating their survival inside the channel (solid arrows). 
axonal regeneration into the cable. The one-way ANOVA performed on the 9-mm date was not statistically significant $(\mathrm{P}>0.05)$, possibly due to a limited number of measures.

\section{$<$ Immunohistochemistry >}

In longitudinal sections of the proximal segment of an SC-seeded channel attached to the host spinal cord, numerous SMI- $31^{+}$axons were seen to exit from the host spinal cord into the tissue cable (Fig. 4). Many of these ingrowing axons extended the whole length of the channel $(9-10 \mathrm{~mm})$. A subset of these fibers was labeled by CGRP antibody, suggestive of PNS origin (Fig. 4). Descending axons from medullary and pontine raphe nuclei $\left(5-\mathrm{HT}^{+}\right.$fibers; Fig. 4) and from locus coeruleus and subcoeruleus nuclei $\left(\mathrm{DBH}^{+}\right.$fibers; Fig. 4) did not grow into the cable instead these fibers accumulated at the host spinal cord cable interface.

Within the graft, implanted adult rat SC survived and associated with ingrowing axons. In sections double stained with SMI-31 (Fig. 4) and S-100 (Fig. 4) antibodies SC-axon units were double labeled longitudinally along the axis of guidance channels, indicating that the grafted SC were in close association with these regenerated axons. Direct evidence for the survival of grafted SC was obtained by pre-labeling the SC in culture with Hoechst 33342 before seeding and grafting. In these cases, numerous labeled SC were observed in the cable 30 days after transplantation confirming that cultured SC survived and were associated with regenerating axons in the guidance channels (Fig. 4). The Hoechst labeling was confined to the graft, suggesting that the implanted SC did not migrate into the host spinal cord for any considerable distance.

At the host-graft interface, reactive gliosis occurred to some degree as indicated by an increase in GFAP immunoreactivity (Fig. 4). Most of the astrocytes were confined to the host spinal cord, but a few cells appeared to extend $0.5-1.0 \mathrm{~mm}$ into the most proximal portion of the graft. The zone of reactive gliosis was the same region where serotonergic and noradrenergic fibers terminated, making a clear interface between host spinal cord and graft.

The results of immunostaining are summarized in Figure 4: 1) Some astrogliosis occurred at the cordgraft interface, and a few astrocytes migrated only into the most proximal portion of the guidance channel (GFAP immunoreactivity). 2) Grafted SC survived and aligned along ingrowing axons (S-100 immunoreactivity). 3) Numerous axons grew into the guidance channel and extended the entire length of the cable (SMI-31 immunoreactivity). 4) Some, but not all, of these axons were of PNS origin (CGRP immunoreactivity). And, finally, 5) supraspinal projections from raphe nuclei (5-HT immunoreactivity) and coeruleus complex (DBH immunoreactivity) did not grow into the guidance channel.

\section{$<$ Retrograde tracing $>$}

In three cases, FB was injected into the middle of the tissue cable to label those neurons whose axons had Frown at least $5 \mathrm{~mm}$ into the guidance channel by 30 days after grafting. In these cases, plastic sections were taken $2 \mathrm{~mm}$ caudal to the injection site to verify axonal growth through that area of the cable and, therefore, past the injection site (Fig. 5A-C). The FBlabeled cells were traced rostrally to $\mathrm{C} 7$ (Fig. 5D, F, $\mathrm{G})$. The closer the spinal cord segment was to the graft, the more cells were labeled (Fig. 5F, G). The labeled cells were confined to laminae III-VIII and X of the spinal gray matter (Fig. 5G). Because labeled cells were not found in lamina IX, where motor neurons are located, the labeling was considered to be in propriospinal neurons. Some DRG neurons were also retrogradely labeled (Fig. 5E, F).

The mean number of labeled neurons in spinal cord was 306 and, in DRG, it was 158 (Fig. 5F); the ratio between the labeled neurons in spinal gray matter vs. DRG was, therefore, approximately $2: 1$ in this paradigm in which spinal roots at levels $\mathrm{T} 6$ and $\mathrm{T} 7$ had been removed at the time of implantation. Thus, 

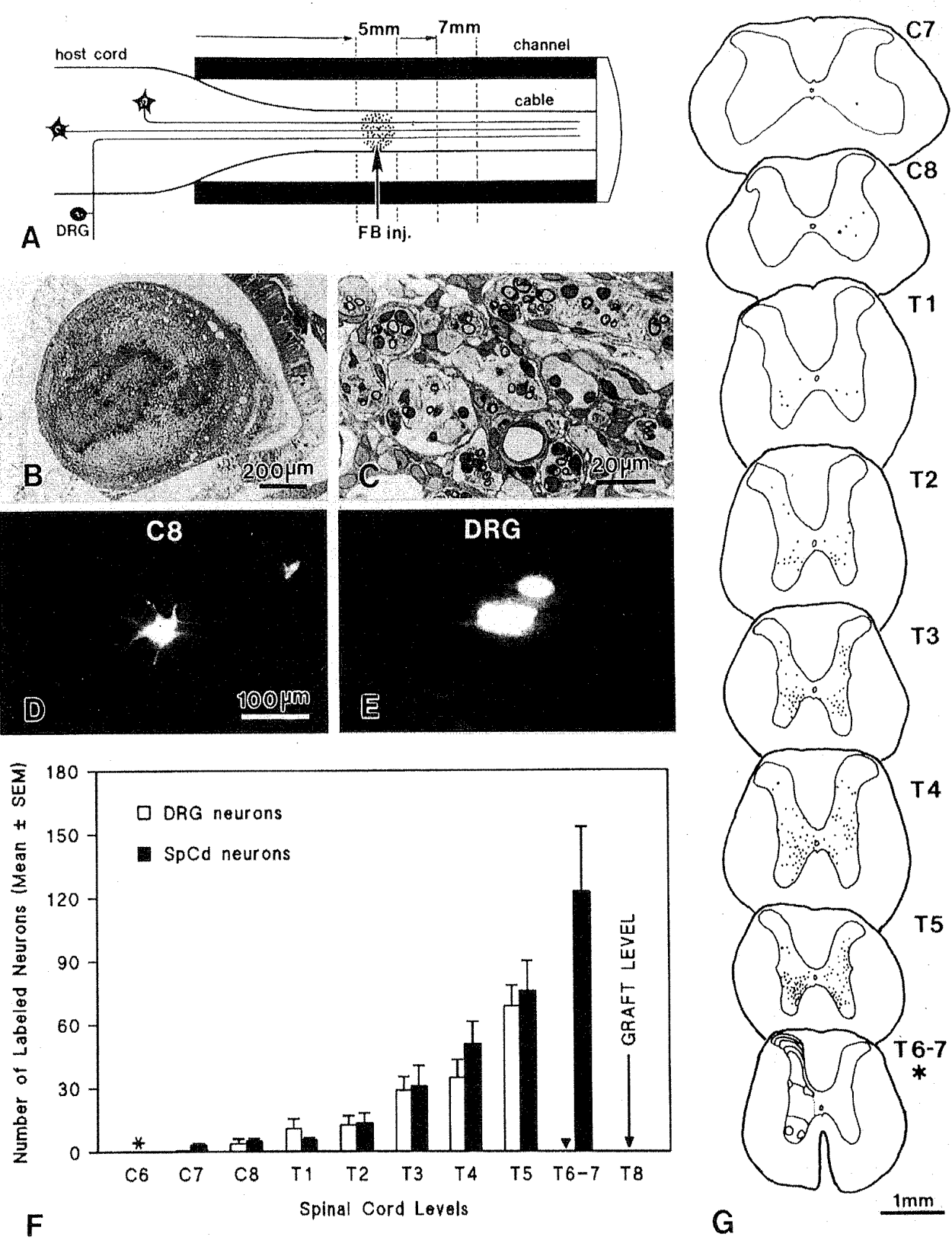

G

Fig. 5. A: The drawing indicates the position of fast blue (FB) injection into an SC-containing cable. B,C: A Toluidine blue-stained (at $7 \mathrm{~mm}$ ) prepared from an FB-injected cable allowed verification of the presence of numerous myelinated axons. The FB-labeled neurons (as in D,E), whose axons regenerated into the graft, were found in both spinal cord gray matter (F, solid bars) and DRG (open bar). Because the spinal roots at T6-T7 were removed, no DRG-labeled cells could be recorded at those levels (arrowhead). Also the lack of labeling at $\mathrm{C} 6$ is indicated by an asterisk. The positions of these labeled neurons in the spinal cord are plotted in G. Their mean numbers were obtained from three cases. The labeled cells at T6T7 were counted but not plotted in G (asterisk), because the sections were cut longitudinally. Scale bar in $\mathrm{D}$ also applies to $\mathrm{E}$. 
propriospinal and DRG neurons extended axons into the SC-containing transplant with diminishing frequency to level C7.

\section{< Gait motion analysis >}

For all pretransected animals, foot trajectories during treadmill locomotion were very consistent (Fig. 6A, B). Variation in step length (horizontal movement) and amplitudes of vertical movements were very small. The right and left hindlimb step cycles were tightly phase-locked with a lag of $180^{\circ}$. There are no movement in horizontal (Fig. 6C) and vertical displacement (Fig. 6D) of the paraplegia animal. But there are some horizontal (Fig. 6E) and vertical (Fig. 6F) movement in 1 month after schwann cell seeded guidance channel grafting into the transected midthoracic spinal cord.

\section{DISCUSSION}

The purpose of this study was to stimulate axonal regeneration after a midthoracic transection in adult rat spinal cord by using purified populations of adult $\mathrm{SC}$ in a capped-end, semipermeable guidance channel model that was, for the first time, applied in the spinal cord. Our results showed as follow, 1) a substantial population of both CNS and PNS axons grew into the SC-seeded guidance channels, 2) implanted SC survived and differentiated in the cable and enhanced axonal regeneration, and 3) both propriospinal and sensory neurons extended axons into the SC-laden grafts from up to $25 \mathrm{~mm}$ rostral to the transection.

\section{< The SC-seeded guidance channel model >}

It has been shown recently that semipermeable guidance channel, seeded with purified populations of SC, very effectively promoted sciatic-nerve regeneration in the PNS [36] and optic nerve [35] and septohippocampal [41] regrowth in the CNS. The physicochemical properties of the guidance channels are important in determining the success of regeneration. For instance, semipermeable guidance channels promote sciatic nerve regeneration if their molecular weight cut-off is $50-100 \mathrm{kDa}$ but not 1,000 $\mathrm{kDa}[2,3]$ and only if their inner wall is smooth [4]. The guidance channels employed here possessed these properties and, in addition were increased in inner diameter to $2.6 \mathrm{~mm}$ in order to host the rostral stump of the spinal cord. The length of each channel was $10 \mathrm{~mm}$ to allow substantial axonal elongation within the channel. The use of the guidance channel ensures transplantation of implants of highly consistent size. As reviewed above, SC secrete a number of trophic factors, express cell adhesion molecules, and synthesize extracellular matrix molecules, which are known to be strong promoters of axonal regeneration. Recent in vivo studies have shown that SCs play a reparative role in spinal cord injury. SC enhanced healing of the graft-host spinal cord interface and hastened axonal elongation into the graft [74]. They promoted axonal growth into spinal cord lesions produced by either a subdural inflatable microballoon [52] or a photochemical lesioning technique [14, 49]. They, along with sensory neurons, influenced corticospinal axons to fasciculate and grow around and beyond a lesion in neonatal rat spinal cord [49].

The efficacy of SC in promoting axonal regrowth has also been shown in other regions of the CNS [37]. For example, by grafting cultured SC and associated ECM into a lesion of the fimbria-fornix pathway, Kromer and colleagues $[48,58]$ found that SC supported axonal regeneration from injured septal cholinergic neurons and subsequent growth into the appropriate target. In contrast, grafting of ECM without SC did not promote such regeneration [58]. The importance of SC in stimulating axonal growth is further supported by the studies in which pieces of SC-containing peripheral nerve (PN) were grafted into transected optic nerves. In these studies, substantial axonal regeneration occurred only if viable SC were present $[11,12]$. When acellular pieces of PN, produced by repetitive freezing and thawing, were grafted, very few axons regenerated 


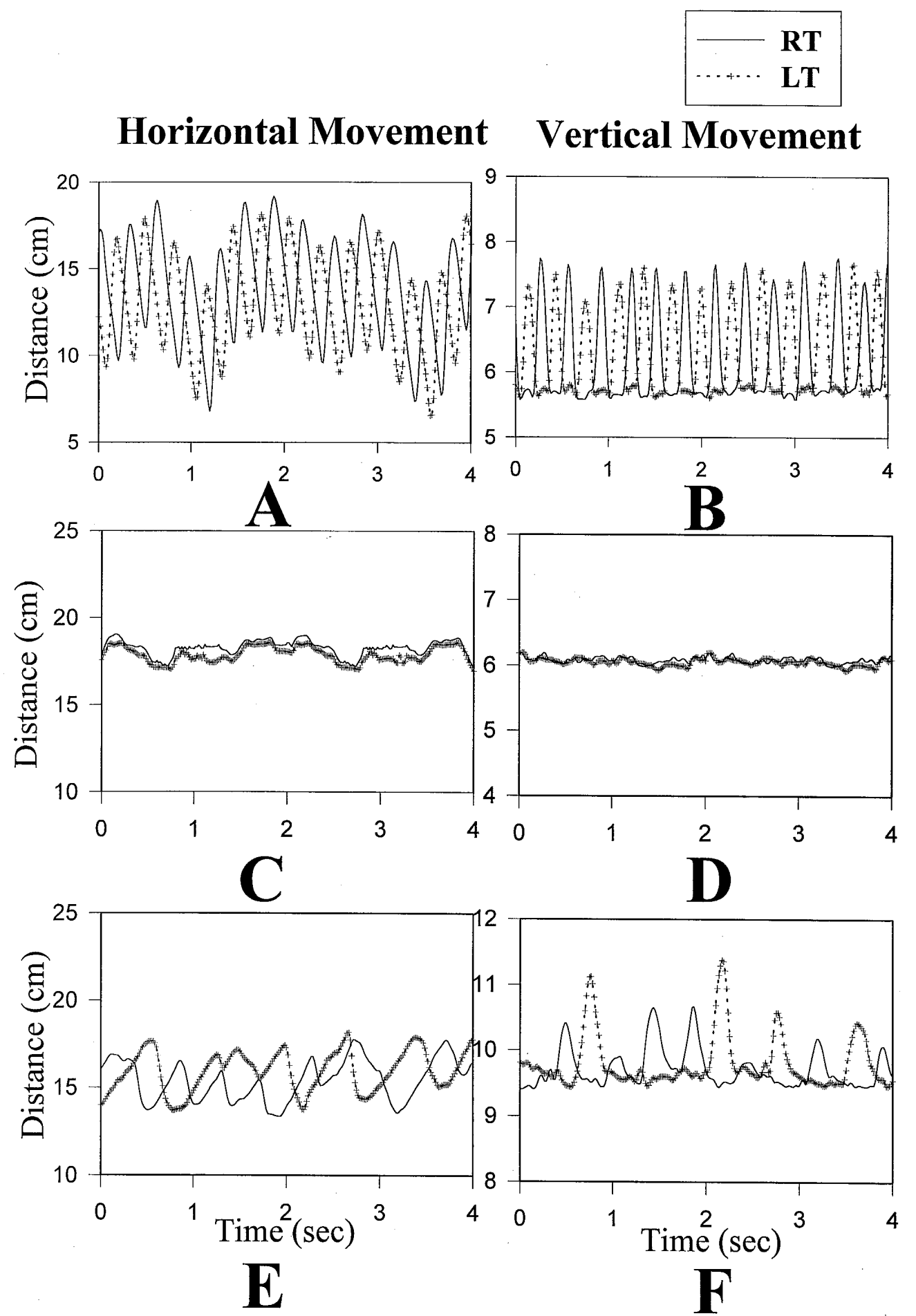

Fig 6. Representative plots the right (solid curve) and left (hatched curve) hindlimb trajectories monitored in pretransected animals. Coordinates of limbs position in two dimensional space are segregated into horizontal (X-axis; A) and vertical (Y-axis; B) components and plotted against time in seconds, e.g. graph A plots the horizontal displacement of the hindlimb while graph B plots the vertical components of the same hindlimb movement. Treadmill speed was $60 \mathrm{~cm} / \mathrm{sec}$. The right and left hindlimb step cycles were tightly phase-locked. Representative plots of the paraplegia animal's hindlimb trajectories (C, D) and restored gait hindlimb trajectories 1 month after schwann cell seeded guidance channel grafting into transected spinal cord (E, F). There are no movements in horizontal (C) and vertical displacement (D) of the paraplegia animal. But there are some horizontal (E) and vertical (F) movement in 1 month after schwann cell seeded guidance channel grafting into the transected midthoracic spinal cord. 
into such grafts $[11,12,72]$.

By combining the guidance channel and purified populations of adult SC, we have developed this unique transplantation model to study spinal cord injury and regeneration in adult animals. In this model, the spinal cord was completely transected at $\mathrm{T} 8$ and a $9-10 \mathrm{~mm}$, and removing the T9-T11 cord segments created gap. Because all of the axons were interrupted by the lesion, and a long tissue cable inside the channel was isolated from the host tissue, the origin of regenerating axons could be convincingly determined by immunohistochemistry and retrograde tracing. In addition, the channel provides a controlled environment in which additional components may be tested. Furthermore, the distal opening of the guidance channel may be uncapped to receive the caudal stump of the spinal cord to assess the regeneration of ascending as well as descending axons [76].

\section{$<\mathrm{SC}$ in channels promote axonal regeneration $>$}

The results of this study clearly demonstrated that SC-seeded, semipermeable guidance channels stimulated CNS axonal regeneration in the transected spinal cord of adult rats. One month after grafting, a vascularized tissue cable was present within the channel and connected to the rostral stump of the host cord in all cases. Within the cable, we estimate that an average of 2,500 myelinated and unmyelinated axons were present. Although some of these axons were of PNS origin, approximately two-thirds of them originated from propriospinal neurons. In the normal spinal cord, these neurons play important roles in establishing intersegmental circuits and could act as a functional relay if regeneration occurs. Interestingly, $\mathrm{SC}$-seeded guidance channels not only promoted axonal growth from neurons in the vicinity of the grafts but also from neurons as far as $25 \mathrm{~mm}$ rostral to the grafts (level C7). The majority of neuron whose axons grew into the channels, however were located within three segments rostral to the grafts.

Grafts of pieces of PN have been successfully used to promote regenerative growth in transected adult rat spinal cord [66]. After grafting sciatic nerve into a 5mm gap in the spinal cord, Richardson et al. [65] found an average of 5,850 or 10,950 myelinated axons in the graft with or without avulsion of DRG, respectively. After horseradish peroxidase injection rostral to the graft, they observed a mean number of 48 labeled neurons in the caudal stump adjacent to the graft; after injection caudal to the graft, the mean number of labeled neurons in the rostral stump was six. When segrnents of autologous tibial nerve were grafted adjacent to the rostral or caudal surfaces of hemisected L1 spinal cord, Houle [43] found that an average of 1,110 and 1,428 myelinated axons were present in the attached grafts, respectively. $\mathrm{He}$ indicated that neurons at least three spinal segments from the lesion site contributed to axonal growth into the graft, and the total number of regenerating neurons per segment (T13, L2, L3, and L4) ranged from 36 to 70. The regenerating neurons were in laminae IV-VIII and X and were located within 10 $\mathrm{mm}$ of the lesion; neither cervical nor brainstem neurons extended axons into the grafts. Houle's work is most pertinent to our study, because the PN grafts apposed either the rostral or caudal stump rather than forming a bridge, though the spinal cord was only hemisected, and implantation was done 4 weeks after lesioning. Fernandez et al. [27] implanted piece of autologous sciatic nerve into a myelotomy of the low thoracic cord with the administration of exogenous NGF. They found that an average of 72 spinal cord neurons were located within a range of 7-13 $\mathrm{mm}$ from the graft site. All these results are consistent, in that only spinal cord neurons extended axons into the transplant after thoracic or lumbar injury. Whereas we did not observe as many myelinated axons as Richardson et al.[65] or Houle [43] did, our transplants of purified populations of SC appeared to recruit neurons at substantial distances, up to $25 \mathrm{~mm}$ away from the injury. This distance far exceeds that at which neurons respond to fetal spinal cord tissue transplants. Jakeman and Reier [44] grafted solid pieces of embryonic cord tissue into hemisection 
aspiration cavities in adult rat lumbar cord and found that most neurons whose axons extended into the transplants were located within $0.5 \mathrm{~mm}$ of the graft site, although some were seen as far as 4-6 mm away.

\section{$<$ SC survived and expressed normal function in the channel >}

SC played an important role in promoting axonal regrowth in our guidance channel model. In control channels without SC, only a small number of myelinated and unmyelinated axons could be found, suggesting that Matrigel alone did not encourage axonal regeneration, and that $\mathrm{SC}$ were essential for regeneration in this paradigm. In order to determine if SC survived in the grafts of postoperative animals, they were labeled in culture with the Hoechst dye before being seeded and grafted into the animal. This marker was chosen for study, because it is a long lasting, nontoxic nuclear marker that spreads little. Moreover, it neither alters SC viability nor affects the ability to form myelin [9]. Hoechst-dye labeling enabled us to conclude that grafted SC did not migrate into host spinal cord, because labeled SC nuclei was essentially confined to the regenerated tissue cable. The labeling also demonstrated clearly that grafted SC survived within the channel for at least 1 month. Moreover, labeled SC nuclei were seen to be associated with ingrowing axons identified by immunoreactivity for neurofilaments. A doublelabeling paradigm for S-100 and SMI-31 antibodies revealed that SC lined up along the axis of the tissue cable forming $\mathrm{SC}$-axon units within the cable. Ultrastructurally SC myelination and ensheathment and basal lamina formation were normal in appearance.

\section{$<$ CNS glial response during regeneration >}

It has been suggested that CNS glia offer an unfavorable microenvironment for axonal elongation in adult mammals $[6,62,63,70]$. For example, regeneration at the interface between host and graft may be inhibited by the astroglial reaction that occurs at the injury site $[62,63]$. When grafts of purified populations of astrocytes within guidance channels were tested in transected sciatic nerve, these cells were found to impede PNS axonal regeneration; when astrocytes were combined with $\mathrm{SC}$, the regenerative capacity usually expressed by SC was diminished [38]. In the present study, intense immunoreactivity for GFAP was observed at the host-graft interface, indicating that reactive gliosis was present, and raising the possibility that it could have impeded CNS axonal regenerative growth, particularly that from supraspinal neurons, into the channel. It should be noted, however, that astrocytes can provide suitable substances for neurite outgrowth in vitro $[20,25]$, and that immature astrocytes have better potential for promoting regenerative axonal growth than do mature astrocytes [47].

A few astrocytes invaded our grafts, but they did not migrate very far into the tissue cable. We mentioned above that SC did not migrate into host cord. These observations are in agreement with findings by others who grafted pieces of peripheral nerve $[11,12,39]$ or SC-seeded polycarbonate tubes [55] into the CNS. These results indicate that, once the axons have penetrated the host-graft interface, they then encounter a favorable SC environment without the potential inhibitory influence of astrocytes.

It has also been demonstrated that oligodendrocyte membrane and CNS myelin contain inhibitory substances that interfere with axonal regeneration in CNS tissue [70]. In spinal cord rendered myelin-free by $\mathrm{X}$-irradiation, corticospinal axons regenerated up to $18.7 \mathrm{~mm}$ beyond a midthoracic lesion made at 2 weeks of age. Corticospinal axons could also regenerate $7-11 \mathrm{~mm}$ beyond spinal cord lesions after these myelin-associated neurite growth inhibitors were neutralized [68]. The inhibitory effects of oligodendrocyte and CNS myelin probably did not diminish axonal regrowth into the guidance channel, because the tissue cable is oligodendrocyte-free. This interpretation, however, depends on the ends of the axons remaining near the transection site and, thus, 
near the channel entrance.

\section{< Are SCs enough? >}

Another reason that axonal regrowth from brain stem or cerebral cortex might not have occurred in our model is that the injury was too far away from the neuronal somata. It has been suggested that the distance between the axotomy site of certain axons and their parent cell somata is crucial [6]. When PNS grafts were inserted into different levels of the spinal cord, long descending axons regenerated into cervical but not midthoracic or lumbar grafts [65]. Similarly, cortical axons did not grow into midthoracic PNS grafts but regenerated into nearby gratts inserted superficially into the cerebrum [6]. SC may not be sufficient to promote regeneration of all CNS tracts, and they may have to be introduced more rostrally to foster growth of the long tracts of the spinal cord. It should be noted that Schnell and Schwab [68] obtained corticospinal tract regenerative growth following a thoracic injury, although the animals were very young. Additional cell types or trophic substances contributing to the regeneration of specific CNS populations need to be studied. Whereas Schnell and Schwab [68] obtained the corticospinal tract regrowth just mentioned, the simultaneous application of neurotrophin-3 (NT-3), along with monoclonal antibodies to neutralize the neurite growth inhibitory proteins of CNS myelin, led to enhanced sprouting of corticospinal axons [69]. Fernandez et al. [27] applied NGF, in combination with PNS grafts, to lesioned rat spinal cord, and found that NGF promoted the regenerative potential of spinal cord as well as DRG neurons. As mentioned previously, one of the advantages of our model is that the channel content can be easily modified genetically engineered cells [30] alone or in combination with SC in an effort to induce more axonal regrowth necessary to provide meaningful functional restoration. The rapidly expanding availability of trophic factors and the possibility of testing them in our model suggest a promising new area of research in spinal cord injury.
Our more recent observation that SC-seeded uncapped channels have the capacity to also engender substantial axonal ingrowth from spinal cord caudal to the channel [76] further supports the potential success of our guidance channel model.

\section{< Motion Analysis >}

In the past, several attempts have been made to utilize kinematic analysis $[10,31]$ in quantitatively studying locomotor function following spinal cord injury or lesions of the vestibular system. However, their analysis are limited because of the small amount of data and/or the narrow parameters used in their studies (e.g. either plotting a few step cycles of the foot trajectories and joint angles of the limbs or analysis of phase relationship between fore and hindlimbs. These studies used time consuming cinematographic methods to measure limb coordinates and joint positions. Recent rapid advances in electronic technology, specifically in the video equipment and personal computers, including supporting software, have made limb coordinate recording and digitization a semi-automatic and quick process. Therefore, numerous step cycles averages in the X-Y coordinate can be efficiently performed. This video assisted, computerized system provides consistent kinematic data. However, the video camera speed of 30 frame pictures per second limits this method. Although our software doubles the frame number during analysis, blurring of limb positions still occurred at moments of peak limb velocity.

The kinematic analysis of treadmill locomotion can be a powerful tool with which to monitor motor functions objectively and quantitatively. Plots of limb trajectories proved to be a useful and easy means of identifying deficits (Fig. 6). Furthermore, many different kinematic variables can be extracted from limb trajectory information such as velocity, acceleration, swing duration and limb coordination. In cats, kinematic analysis techniques were used to study locomotion and analyze trajectories of joint angles. In rats, skin flaps tend to mask limb joint positions and 
therefore, make joint angles measurements impratical as a means of kinematic data collection. Foot trajectories, measured in two dimensional space, could represent limb movement in real time. The difficulty of testing animals immediately after injury poses one drawback of this method. Therefore, it should be supplemented by other behavioral tests such as the auditory startle reflex [33]. In the early stage of recovery, the injured animal could not move as fast as it had pre-SCI. Therefore, one can argue that the alteration of the kinematic variables seen in this study may be the result of the different in walking speeds rather than the neuronal injuries. This possibility has been carefully examined in normal rats and the kinematic analysis will be presented in a separate paper [18]. Also, the kinematics of the forelimbs provided a very important clue that the observation made after the spinal cord injury is not the result of different walking speeds.

\section{REFERENCES}

1. Acheson A., Barker PA, Alderson RF: Detection of brain-derived neurotrophic factor-like activity in fibroblasts and Schwann cells: Inhibition by antibodies to NGF. Neuron 7: 265-275, 1991

2. Aebischer P., Guénard V, Winn SR: Blind-ended semipermeable guidance channels support peripheral nerve regeneration in the absence of a distal nerve stump. Brain Res 454: 179-187, 1988

3. Aebischer P, Guénard V, Brace S: Peripheral nerve regeneration through blind-ended semipermeable guidance channels: Effect of the molecular weight cut off. J Neurosci 9: 35903595, 1989

4. Aebischer P, Guénard V, Valentini RF: The morphology of regenerating peripheral nerves is modulated by the surface microgeometry of polymeric guidance channels. Brain Res 531: 211-218, 1990

5. Aebischer P., Wahlberg L, Winn SR et al: Macroencapsulation of dopamine-secreting cells by coextrusion with an organic solution.
Biomaterials 12: 50-56, 1991

6. Aguayo AJ: Axonal regeneration from injured neurons in the adult mammalian central nervous system. In Cotman CW (ed): Synaptic Plasticity. New York: The Guilford Press, 1985, pp457-484

7. Alstermark B: Effect of dorsal column transection in the upper cervical segments on visually guided forelimb movements. Neuroscie Res 3: 462-466, 1986

8. Bandtlow CE, Heumann R, Schwab ME et al: Cellular localization of nerve growth factor synthesis by in situ hybrldization. EMBO J 6: 891899, 1987

9. Baron-Van Evercooren A, Gansmuller A: Hoechst 33342, a suitable fluorescent marker for Schwann cells after transplantation in the mouse spinal cord. Neurosci Lett 131: 241-244, 1991

10.Berhrmann DL: Spinal cord injury produced by consistent mechanical displacement of the cord in rats: Behavioral and histologic analysis. J Neurotrauma 9: 197-127, 1992

11.Berry M, Rees L, Hall S et al: Optic axons regenerate into sciatic nerve isograft only in the presence of Schwann cells. Brain Res Bull 20: 223-231, 1988

12. Berry M, Hall S, Follows R et al: Response of axons and glia at the site of anastomosis between the optic nerve and cellular and acellular sciatic nerve graft. J Neurocytol 17: 727-744, 1988

13.Bixby JL, Lilien J, Reichardt LF: Identification of the major proteins that promote neuronal process outgrowth on Schwann cells in vitro. J Cell Biol 107: 353-361, 1988

14.Bunge MB: Schwann cell regulation of extracellular matrix biosynthcsis and assembly. In PJ Dyck, PK Thomas, JW Griffin, PA Low, JF Poduslo (eds): Peripheral Neuropathy. Philadelphia: W.B. Saunders Company, 1993, pp299-316

15. Bunge RP, Bunge MB, Eldridge CF: Linkage between axonal ensheathment and basal lamina production by Schwann cells. Ann Rev Neurosci 9: 305-328, 1986 
16. Bunge MB, Paino CL, Fernandez-Valle C: Implantation of cultured Schwann cells to foster repair in injured mammalian spinal cord. In Bell E (ed): Tissue Engineering: Current Perspectives. Boston: Birkhauser, 1993, pp48-57

17. Cabasso I: Hollow fiber membranes. In KirkOthner (ed): Encyclopedia of Chemical Technology. Vol. 12. New York: John Wiley and Sons, 1980, pp492-517

18. Cho KS, Madsen PW, Marcillo AE, Kim JH: Growth related changes in limb kinematic parameters of locomotion in normal rats. Neuroscie Abstr 19: 147, 1993

19.Daniloff JK, Levi G, Grumet M, et al: Altered expression of neuronal cell adhesion molecules induced by nerve injury and repair. J Cell Biol 103: 929-945, 1986

20.David S: Neurite outgrowth from mammalian CNS neurons on astrocytes in vitro may not be mediated primarily by laminin. J Neurocytol 17: 131-144, 1988

21.Davis GE, Varon S, Engvall E et al: Substratum binding neurite-promoting factors: Relationships to laminin. TINS 8: 528-532, 1985

22.Eidelberg E, Story JL, Meyer BL et al: Stepping by chronic spinal cats. Exp Brain Res 40: 241-246, 1980

23.Eidelberg E, Story JL, Walden JG et al: Anatomical correlates of return if locomotor function after partial spinal cord lesions in cats. Exp Brain Res 42: 81-88, 1981

24.English AW: The function of the lumbar spine during stepping in the cat. J Morphol 165: 55-66, 1980

25.Fallon JR: Preferential outgrowth of central nervous system neurites on astrocytes and Schwann cells as compared with nonglial cells in vitro. J Cell Biol 100: 198-207, 1985

26. Fawcett JW, Keynes RJ: Peripheral nerve regeneration. Annu Rev Neurosci 13: 43-60, 1990

27.Fernandez E, Pallini R, Mercanti D: Effects of topically administrated nerve growth factor on axonal regeneration autografts implanted in the spinal cord of rats. Neurosurgery 26: 37-42, 1990

28. Fields RD, Le Beau JM, Longo FM et al: Nerve regeneration through artificial tubular implants. Prog. Neurobiol 33: 87-134, 1989

29. Friedman B, Scherer SS, Rudge JS et al: Regulation of ciliary neurotrophic factor expression in myelin-related Schwann cells in vivo. Neuron 9: 295-305, 1992

30.Gage FH, Kawaja MD, Fisher LJ: Genetically modified cells support axonal growth in the central nervous system of adult rats. Applications for intracerebral grafting. TINS 14: 32-33, 1991

31. Gale K, Kerasidis H, Wrathall JR: Spinal cord contusion in the rat: behaviourral analysis of functional neurologic impairment. Exp Neurol 8: 123-134, 1985

32. Goldberger ME, Bregman BS, Vierck CJ et al: Criteria for assessing recovery of function after spinal cord injury: behavioral methods. Exp Neurol 107: 113-117, 1990

33. Gruner JA: Comparison of vestibular and auditory startle response in the rat and cat. J Neurosci Methods 27: 13-23, 1989

34.Gruner JA, Altman J, Spivack N: Effects of arrested cerebellar development on locomotion in the rat. Cinematographics and electromyographic analysis. Exp Brain Res 40: 361-373, 1980

35.Guénard V., Morrissey TK, Kleitman $\mathrm{N}$ et al: Cultured syngeneic adult Schwann cells seeded in synthetic guidance channels enhance sciatic and optic nerve regeneration. Soc Neurosci Abstr 17: 565, 1991

36. Guénard V, Kleitman N, Morrissey TK et al: Syngeneic Schwann cells derived from adult nerves seeded in semipermeable guidance channels enhance peripheral nerve regeneration. J Neurosci 12: 3310-3320, 1992

37.Guénard V, Xu XM, Bunge MB: The use of Schwann cell trasplantation to foster central nervous system repair. Semin Neurosci 5: 401411, 1993

38. Guénard V, Aebischer P, Bunge RP: The astrocyte inhibition of peripheral nerve regeneration is 
reversed by Schwann cells. Exp Neurol 126: 4460, 1994

39. Hall S, Berry M: Electron microscopic study of the interaction of axons and glia at the site of anastomosis between the optic nerve and cellular or acellular sciatic nerve grafts. J Neurocytol 18:171-184, 1989

40.Humann R, Korsching S, Bandtlow C et al: Changes of nerve growth factor synthesis in nonneuronal cells in response to sclatic transection. J Cell Biol 104: 1623-1631, 1987

41.Hoffman D, Aebischer P: Septo-hippocampal regeneration hrough biosynthetic bridges containing adult Schwann cells. Soc Neurosci Abstr 18: 627, 1992

42. Holets VR, Hökfelt T, Ude J et al: A comparative study of the immunohistochemical localization of a presumptive proctolin-like peptide, thyrotropin releasing hormone and 5-hydroxytryptamine in the rat central nervous system. Brain Res 408: 141153,1987

43. Houle JD: Demonstration of the potential for chronically injured neurons to regenerrate axons into intraspinal peripheral nerve grafts. Exp Neurol 113: 1-9, 1991

44.Jakeman LB, Reier PJ: Axonal projections between fetal spinal cord, trasplants and the adult rat, spinal cord: A neuroanatomical tracing study of local interractions. J Comp Neurrol 307: 311334, 1991

45. Kato M, Murakami S, Yasuda K et al: Disruption of fore-and hindlimb coordination during overground locomotion in cats with bilateral serial hemisection of the spinal cord. Neuroscie Res 2: 27-47, 1984

46. Kleitman N, Simon DK, Schachner M et al: Growth of embryonic ertinal neurites elicited by contact with Schwann cell surfaces is blocked by antibodies to L 1. Ex. Neurrol 102: 298-306, 1988

47. Kliot M, Smith GM, Siegal JD et al: Astrocytepolymer implants promote regeneration of dorsal root fibers into the adult mammalian spinal cord. Exp Neurol 109: 57-69, 1990
48. Kromer LF, Cornbrooks CJ: Transplants of Schwann cell cultures promote axonal regeneration in the adult mammalian brain. Proc Natl Acad Sci USA 82: 6330-6334, 1985

49. Kuhlengel KR, Bunge MB, Bunge RP et al: Implantation of cultured sensory neurons and Schwann cells into lesioned neonatal rat spinal cord. II. Implant characteristics and examation of corticospinal tract growth. J Comp Neurol 293: 74-91, 1990

50.Le Beau JM, LaCorbiere M, Powell $\mathrm{HC}$ et al: Extracellular fluid conditioned during peripheral nerve regeneration stimulates Schwann cell adhesion, migration and proliferation. Brain Res 459: 93-104, 1988

51.Longo FM, Hayman EG, Davis GE et al: Neuritepromoting factors and extracellular matrix components accumulating in vivo within nerve regeneration chambers. Brain Res 309: 105-117, 1984

52. Martin D, Schoenen J, Delrée P et al: Grafts of syngenic cultured, adult dorsal root ganglionderived Schwann cells to the injured spinal cord of adult rats: Preliminary morphological studies. Neurosci Lett 124: 44-48, 1991

53. Meyer M, Matsuoka I, Wetmore C et al: Enhanced synthesis of brain-derived neurotrophic factor in the lesioned peripheral nerve: Different mechanisms are responsible for the regulation of BDNF and NGF mRNA. J Cell Biol 119: 45-54, 1992

54.Montero-Menei CN, Pouplard-Barthelaix A, Gumpel M et al: Pure Schwann cell suspension grafts promote Brain Res 570:198-208, 1992

55. Montgomery CT, Robson JA: New method of transplanting purified glial cells into the brain. J Neurosci Methods 32: 135-141, 1990

56. Montgomery CT, Robson JA: Implants of cultured Schwann cells support axonal growth in the central nervous system of adult rats. Exp Neurol 122: 107-124, 1993

57. Morrissey TK, Kleitman N, Bunge RP: Isolation and functional characterization of Schwann cells 
derived from adult peripheral nerve. J Neurosci 11: 2433-2442, 1991

58. Neuberger TJ, Cornbrooks CJ, Kromer LF: Effects of delayed transplantation of cultured Schwann cells on axonal regeneration from central nervous system cholinergic neurons. J Comp Neurol 315: 16-33, 1992

59.Paino CL, Bunge MB: Induction of axon growth into Schwann cell implants grafted into lesioned adult rat spinal cord. Exp Neurol 114: 254-257, 1991

60.Porter S, Clark MB, Glaser L et al: Schwann cells stimulated to proliferate in the absence of neurons retain full functional capacity. J Neurosci 6: 30733078, 1986

61.Ramöny Cajal, S: Degeneration and Regeneration of the Nervous System. Translated by RM May. New York: Oxford University Press, 1928

62. Reier PJ, Houle PD: The glial scar: Its bearing on axonal elongation and transplantation approaches to CNS repair. In Waxman SG (ed): Functional Recovery in Neurological Disease, Vol. 74. New York: Raven Press, 1988, pp 87-138.

63. Reier PJ, Stensaas LJ, Guth L: The astrocytic scar as an impediment to regeneration in the central nervous system. In Kao CC, Bunge RP, and Reier PJ (eds): Spinal Cord Reconstruction. New York: Raven Press, 1983, pp163-196.

64.Rende M, Muir D, Ruoslahti E. et al: Immunolocalization of ciliary neuronotrophic factor in adult rat sciatic nerve. Glia 5: 25-32, 1992

65.Richardson PM, McGuinness UM, and Aguayo AJ: Axons from CNS neurones regenerate into PNS grafts. Nature 284: 264-265, 1980

66. Richardson PM, Issa VMK, Aguayo AJ: Regeneration of long spinal axons in the rat. J Neurocytol 13: 165-182, 1984

67. Schachner M: Functional implications of glial cell recognition molecules. Semin Neurosci 2: 497507, 1990

68. Schnell L, Schwab ME: Axonal regeneration in the rat spinal cord produced by an antibody against mvelin-associated neurite growth inhibitors. Nature 343: 269-272, 1990

69. Schnell L, Schneider R, Kolbek R et al: Neurotrophin-3 enhances sprouting of corticospinal tract during development and after adult spinal cord lesion. Nature 367: 170-173, 1994

70.Schwab ME: Myelin-associated inhibitors of neurite growth. Exp Neurol 109: 2-5, 1990

71. Smith GV, Stevenson JA: Peripheral nerve grafts lacking viable Schwann cells fail to support central nervous system axonal regeneration. Exp Brain Res 69: 299-306, 1988

72.Uzman BG, Villegas GM: Mouse sciatic nerve regeneration through semipermeable tubes: A quantitative model. J Neurosci Res. 9: 325-338, 1983

73.Uzman BG, Snyder DS, Villegas GM: Status of peripheral nerve regeneration. In F Seil (ed): Neural Regeneration and Transplantation. New York: Alan R. Liss, Inc., 1989, pp15-28

74. Wrathall JR, Rigamonti DD, Braford MR et al: Reconstruction of the contused cat spinal cord by the delayed nerve graft, technique and cultured peripheral nonneuronal cells. Acta Neuropathol 57: 59-69, 1982

75.Xu XM, Guénard V, Kleitman N et al: Axonal growth into Schwann cell-seeded guidance channels grafted into transected adult rat spinal cord. Soc Neurosci Abstr 18: 1479, 1992

76.Xu XM, Guénard V, Bunge MB: Rostral and caudal axonal regeneration into Schwann cellseeded guidance channels grafted into a gap in adult rat spinal cord. Soc Neurosci Abstr 19: 681, 1993

77.Zamboni L, De Martino C: Buffered picric acidformaldehyde: A new, rapid fixative for electron microscopy. J Cell Biol 35: 148A, 1967 


\section{Reviewer's comment : \\ Yoichi Katayama \\ Department of Neurological Surgery, Nihon University School of Medicine Tokyo, Japan}

This article provides an outstanding example of a laboratory approach to clinical problems in neurosurgery. The authors confirmed that the Schwann cell-seeded guidance channel, when transplanted in the transected spinal cord, strongly stimulate axonal regeneration. More importantly, they clearly demonstrated restoration of locomotor function by kinematic analysis. It is interesting to note that $5 \mathrm{HT}$ and DBH immunoreactive axons were not detected within the tissue cable of guidance channels. The data obtained offer us hope that the most appropriate therapeutic approach to the spinal cord injury can be defined with persent aninmal model in the future.

\section{Reviewer's comment : \\ Hideaki Iizuka \\ Department of Neurosurgery, Kanazawa Medical University \\ Ishikawa, Japan}

This article demonstrates morphological and functional evidences of axonal regeneration in the adult rat spinal cord using unique model, Schwann cell-seeded guidance channel.

The histological findings and the results of tract tracing study strongly suggest that central axons regenerate in the propriospinal tracts but not in the descending pathway by Schwann cell guidance.

It is unclear whether regenerating propriospinal fibers influence functional recover. In this experiment, Fast Blue (tracer) was injected into a Schwann cell containing cable. If the labeled neurons are identified in the rostral cord segments of the cable graft after Fast Blue injection into the caudal lumbar segments (not into the graft), that will be more apparent evidence of the graft working for axonal regeneration. 